\title{
Functional neurological deficit but not epilepsy alone increased the risk of death in childhood epilepsy
}

Camfield CS, Camfield PR, Veugelers PJ. Death in children with epilepsy: a population-based study. Lancet 2002;359:1891-5.

\section{QUESTION: What are the risk factors for, and frequency of, all cause mortality in children with epilepsy?}

\section{Design}

Inception cohort of children who developed epilepsy between 1977 and 1985 and were followed up for $\leq 22.5$ years.

\section{Setting}

Nova Scotia, Canada.

\section{Patients}

692 children (50\% girls) who developed epilepsy ( $\geq 2$ unprovoked seizures) between 1977 and 1985 in Nova Scotia. Exclusion criteria included acute provoking factors for seizures, evidence of progressive neurological disease, and children who had had only neonatal seizures, unless the seizures had stopped by the time of neonatal discharge from hospital and later recurred without provocation.

\section{Assessment of prognostic factors}

In 1999, names and birth dates of the cohort were linked to the Nova Scotia provincial death and marriage registries (Division of Vital Statistics). For women $>15$ years of age, the marriage registry was checked to ascertain whether the names had been changed by marriage, and the marriage name was also checked against the death registry. Death certificates, necropsy reports, and physician records of children who had died were examined and families contacted to verify if sudden unexpected death in epilepsy could have occurred. Duration of follow up of survivors was established by the last date they were known to be alive. Association between mortality and prognostic factors was assessed using univariate and multivariate analyses.

\section{Main outcome measures}

Incidence of all cause mortality in childhood epilepsy.

\section{Main results}

$3.8 \%$ of patients died. Incidence of all cause mortality was greater in the study cohort than in the general population of Nova Scotia (standardised mortality ratio for 1980-89 5.30, 95\% CI 2.29 to 8.32, and for 1990-99 8.80 , CI 4.16 to 13.43 ). Kaplan-Meier curves showed a mortality rate of $6.1 \% 20$ years after onset of epilepsy compared with $0.88 \%$ in the reference population. Both univariate and multivariate analyses showed that the incidence of all cause mortality was greater in children who had sufficient disorders to cause functional neurological deficit than in those who did not (table). Univariate analysis showed that age at onset and type of epilepsy were associated with all cause mortality. However, this effect diminished after adjusting for neurological deficit (table).

\section{Conclusion}

Children with epilepsy, but without functional neurogeneral population; however, children with epilepsy who also had other severe neurological disorders had an increased risk of death.

Sources of funding: no external funding.

For correspondence: Dr C S Camfield, Division of Child

Neurology, IWK Health Centre, Halifax, Nova

Abstract also appears in Evidence-Based Nursing. logical deficit, had a similar risk of death to that of the Scotia, Canada.

Association between all cause mortality and prognostic factors in children with epilepsy*

\begin{tabular}{|c|c|c|c|}
\hline Prognostic factor & Comparison & $\begin{array}{l}\text { Univariate RR } \\
(95 \% \text { CI) }\end{array}$ & $\begin{array}{l}\text { Multivariate RR } \\
\text { (CI)† }\end{array}$ \\
\hline Sex & Girl $v$ boy & 1.5 (0.7 to 3.2$)$ & $1.3(0.6$ to 2.9$)$ \\
\hline \multirow[t]{2}{*}{ Age at onset (years) } & $1-5 \vee 0$ & $0.9(0.3$ to 1.5$)$ & $1.5(0.6$ to 3.9$)$ \\
\hline & $6-16 \vee 0$ & $0.3(0.1$ to 0.8$)$ & $1.7(0.5$ to 6.1$)$ \\
\hline \multirow[t]{2}{*}{ Epilepsy type } & $\begin{array}{l}\text { Generalised or partial } \\
\text { SG } v \text { SG }\end{array}$ & $0.2(0.1$ to 0.5$)$ & 0.7 (0.3 to 1.7$)$ \\
\hline & Absence $v$ SG & $0.1(0.0$ to 0.6$)$ & $0.8(0.1$ to 8.1$)$ \\
\hline Neurological disorder & SND $v$ none & 22.2 (8.3 to 59.2$) \ddagger$ & 22.0 (7.0 to 69.7$) \ddagger$ \\
\hline
\end{tabular}

${ }^{*} \mathrm{SG}=$ secondary generalised epilepsy; SND = severe neurological disorder. RR and $\mathrm{Cl}$ defined in glossary. †Multivariate RRs are adjusted for other prognostic factors. fStatistically significant.

\section{COMMENTARY}

This interesting population-based cohort study by Camfield et al of children with epilepsy in Nova Scotia, Canada largely dispels the notion of "idiopathic" sudden death in paediatric epilepsy. All children (n=692) who developed epilepsy between 1977 and 1985 in the province were entered into a database and followed up in 1999. The authors grouped the patients into 1 of 3 categories: absence epilepsy, partial epilepsy without secondary generalisation, and (confusingly for the general reader) "secondary generalised epilepsies" including "epilepsies with generalised seizure types such as akinetic or astatic, myoclonus, tonic, and infant spasms".

Importantly, the 26 deaths were not evenly distributed among groups: $1 \%$ in the absence epilepsy, $2 \%$ in the partial epilepsy, and 15\% in the "secondary generalised epilepsies". Of the 26 deaths, 22 were not unexpected and resulted from severe ongoing disorders sufficient to cause functional neurological deficit. Of the 4 unexpected deaths, 2 were suicides, one a homicide, and only one was of questionable cause (even in this instance, the 21 year old patient had experienced several seizures in sleep on the day she was found dead in bed).

Multivariate regression analysis of risk of death indicated no risk increase for sex, age of onset, or epilepsy type, whereas the presence of a pre-existing neurological disorder raised the relative risk of death in the cohort by the very considerable factor of 22 $(\mathrm{p}<0.001$ for comparing risk of death between children with and without an ongoing neurological deficit). The rate of death of patients without severe neurological deficit was $0.8 \%$ and did not differ from the normal reference population.

In summary, the message is that paediatric epilepsy patients do not die more often than other children unless there is ongoing neurological deficit. The spectre of sudden death in paediatric epilepsy, unrelated to seizures, is largely dispelled by this study and should comfort affected children, parents, and their physicians.

Paul O'Connor, MD

St Michael's Hospital Toronto, Ontario, Canada 